\title{
Nut Shells as Adsorbents of Pollutants: Research and Perspectives
}

\begin{abstract}
Maria I. Papadaki ${ }^{1 *}$, Didilia lleana Mendoza-Castillo², Hilda Elizabeth Reynel-Avila ${ }^{2}$, Adrian Bonilla-Petriciolet ${ }^{2}$ and Stavros Georgopoulos ${ }^{1}$

${ }^{1}$ Department of Environmental Engineering, University of Patras, Agrinio, Greece, ${ }^{2}$ Department of Chemical Engineering, Instituto Tecnologico de Aguascalientes, Aguascalientes, Mexico
\end{abstract}

Shells, kernels, and other wastes have been investigated by researchers as potential adsorbents for a number of pollutants like methylene blue (MB), Remazol Rot RB, acid blue 80 , acid blue 324 , or as raw materials for the production of activated carbons and biochars to serve the same objective. Activated carbons formed by such wastes have been found to remove different heavy metals like uranium, arsenic, and cadmium while their biochars removed others like lead and copper. Furthermore, the production of these adsorbents can be combined with additional ways of valorization of this type of waste like bio-oil or bio-gas generation or even added-value materials extraction. In this work, conducted research on the ability of pistachio, pecan, cashew nut, and castor seed shells to selectively adsorb and thus remove pollutants from synthetic wastewaters is being shown. This type of research needs to be expanded in order to incorporate competitive adsorption, adsorbents regeneration, and recovery of adsorbates and to evaluate their performance with real wastewaters, before they find their way to large scale applications for the removal of the respective compounds from natural waters and wastewaters. An appropriate life cycle assessment is also necessary for the evaluation of the environmental benefits arising from their use.

Keywords: nutshell biochar, heavy metal adsorption, pistachio nutshell, dye adsorption, activated carbons

\section{INTRODUCTION}

A great number of researchers are focusing their interest on the formation of activated carbons by means of waste materials residual biomass. One type of such biomass is the shells of nuts (Figure 1).

There is increasing evidence of the health benefits arising from nuts. Their scientifically backed up nutritive characteristics have given impetus to a significant rise in their production. At the same time, the continuous improvement of the quality of life is still moving through routes which favor excessive packaging and employment of single use disposable products. This has resulted in increased pollution of air and water but also in substantial solid waste accumulation. The management of solid wastes requires inventive means of action, some of which may sprout from the principles of cyclic economy. Furthermore, the increasing pollution of waters puts pressure on the scientific community to develop novel methods and means for their decontamination and purification. As such, it become obvious that research aiming at the development of reusable products seen via a systems approach is imperative. Along those lines the use of waste nut shells for water decontamination and purification can provide a solution to the latter two problems; 


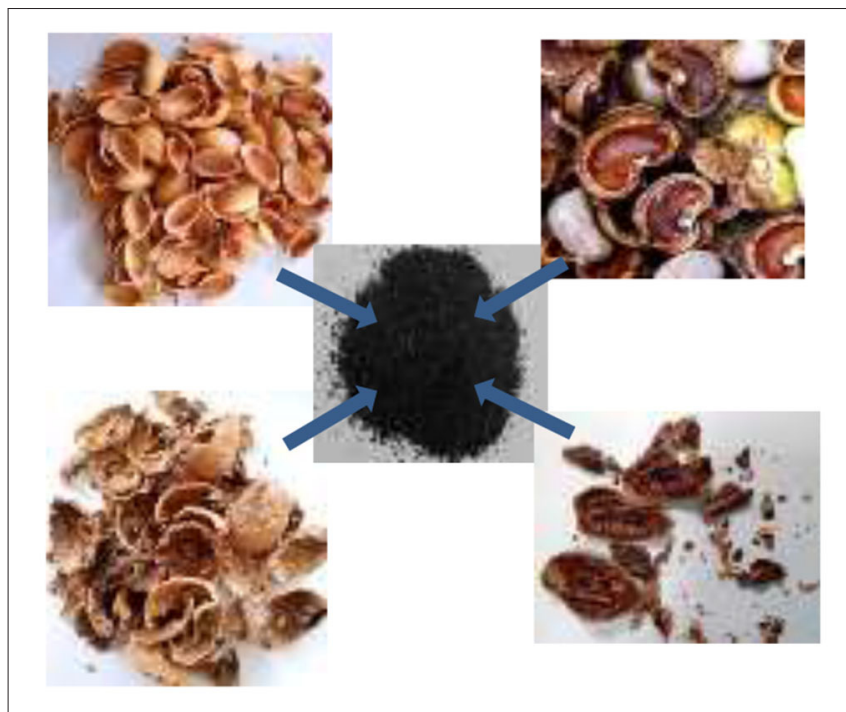

FIGURE 1 | Nutshells for the formation of activated carbons.

at the same time, the expansion of the former, i.e., a potential rise in the nut cultivation and production of nuts can be viewed not only as a desirable form of food but as an excellent source of additional adsorbents.

One of the key difficulties in the valorization of waste biomass is the feedstock collection. Nuts are increasingly used by the food industry. They are usually peeled on-site; making the collection of this primary waste easy (Bello-Huitle et al., 2010). Therefore, such an adsorbent feedstock is easily obtainable. Nut kernels are appropriate for the development of activated carbons because they contain a high amount of carbon.

Activated carbons from this feedstock are formed via the pyrolysis of the raw shells, during which other added value products such as bio-oil can also be obtained (Zazycki et al., 2018; Dashtizadeh et al., 2019). The development of activated carbons from nutshells often involves chemical and physical activation using $\mathrm{KOH}, \mathrm{ZnCl}_{2}, \mathrm{H}_{2} \mathrm{SO}_{4}, \mathrm{H}_{3} \mathrm{PO}_{4}$, and $\mathrm{CO}_{2}$, prior to the pyrolysis step (e.g., Aguayo-Villarreal et al., 2017). Physical activation can be achieved in different ways for instance using steam. Activation of the untreated shells before they are subjected to pyrolysis creates many different sizes of pores both in the interior and the external surface of the employed biomass. When acids are used for pre-treatment, the respective acid anions are incorporated into the produced activated carbons. The porosity of the formed activated carbon depends on the method and extent of activation, while its carbonization depends on the pyrolysis temperature according to Bello-Huitle et al. (2010). However, all this treatment also affects the costs of the formed product simultaneously reducing the environmental benefits resulting in its usage.

Presently, a great number of researchers are focusing on the valorization of waste of different types; wastes are viewed as potential candidates in numerous applications, food supplements, and natural medicinal products extraction, biofuel, and natural adsorbents production being amongst them
(Santzouk et al., 2019; Coelho et al., 2020; Criado and Martin, 2020; Roda-Serrat et al., 2020; Madeddu et al., 2021).

This work focuses on the potential uses of pistachio, cashew, and pecan nutshells, and castor seed hull and more specifically in their uses as adsorbents of pollutants in wastewaters and surface waters. These compounds, after a minimal physical treatment can be used as they are collected. Alternatively, they can be employed as activated carbon precursors and be subsequently used for a variety of applications. A review of their effectiveness as adsorbents is presented in this work.

\section{NUTSHELLS}

\section{Pistachio Nut Shell}

According to the International Nut and Dried Fruit Council statistics, the last 5-years average of the world pistachio production amounted to just above 250 Mton (in-shell basis). USA, Iran, and Turkey produced $93 \%$ of the world share with 44,34 , and $15 \%$, respectively. Pistachio exports for the respective period was just over 130 Mton, with Iran and the USA exporting 38 and 34\%, respectively. Exports from Turkey are not shown. On the contrary, Turkey is an importer of this nut; this is an indication that its production is most likely consumed locally and that local production is not sufficiently high so as to satisfy the country's needs (International nut \& Dried Fruits statistical. yearbook, 2017/2018).

There have been a good number of publications in recent years focusing on the valorization of the shells of this nut. A great number of them focus on its use for the formation of activated carbons to be used as adsorbents.

The demand for activated carbons for a variety of applications is fast expanding. However, the traditionally formed activated carbons have a high cost of production. The commercially available activated carbons are expensive. Encountering cheaper but efficient alternatives is one of the targets of the presently conducted research worldwide. For the purpose of the valorization of suitable waste biomass, pistachio nut shells (Figure 2) are an excellent option. Much of the research into this field has been conducted by researchers in Turkey. Turkey is a country which has the most suitable climate for pistachio cultivation (Sahin et al., 2018). The fact that this crop is produced and consumed locally provides an incentive to accordingly valorize this waste. For example, it can form a valuable means of wastewaters decontamination and in particular for the removal of dyes, a problem which the researchers of the country are aiming to resolve.

However, as shown later, additional studies have been conducted using it as fuel, as a source of antioxidants, for the synthesis of useful chemicals, and for ion-lithium batteries.

Pistachio nut shell has been used as adsorbent raw material by a number of researchers. In most cases it has been suitably treated, so that an appropriately activated carbon is formed, which has subsequently been used for the removal of different pollutants from different media, mainly surrogate wastewaters. A summary of the publications involving pistachio hulls as adsorbents is shown in Table 1, which will form the basis for a subsequent comparison, 

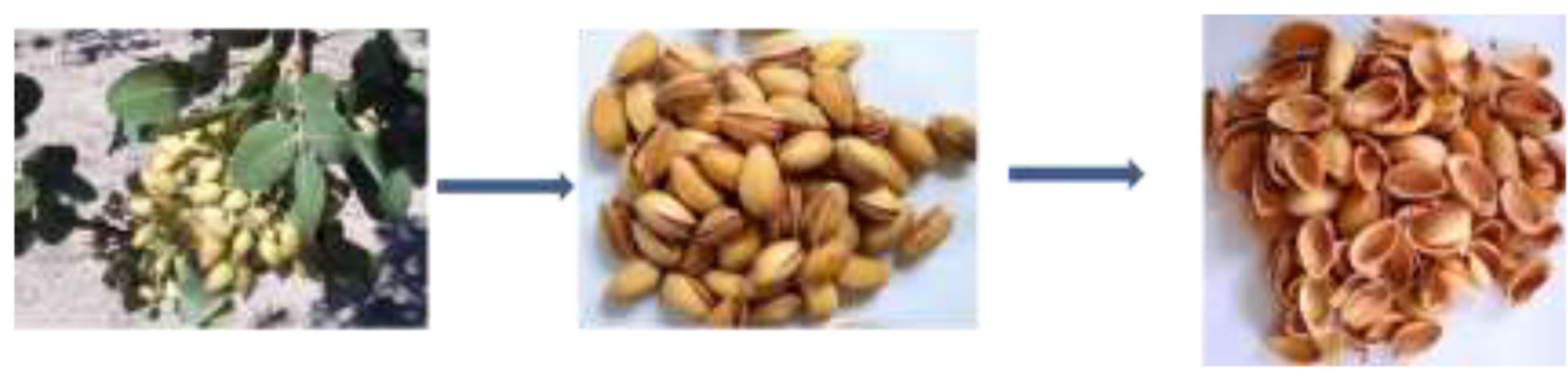

FIGURE 2 | Pistachio tree, dried pistachio nuts, and pistachio nutshells.

while a brief summary of the conducted research is shown below.

Copper-doped zinc sulfide nanoparticles loaded on activated carbon waste which was formed by pistachio nut shell were used for the removal of naphthol green B (NG-B) and phenol red (PH-R) dye from synthetic wastewaters. The study involved catalyst characterization and identification of optimal experimental conditions via appropriate screening based on experimental measurements and central composite design. The experimental study was performed with simultaneous sonication of the solution and at the optimal conditions they achieved $99 \%$ removal of the dyes in a very short time. The kinetics obtained were of pseudo-second order (Masoudian et al., 2018).

Sahin et al. (2018) employed pistachio shells for the fabrication of small pore carbon molecular sieves. They were produced via benzene deposition at a range of temperatures and deposition times. The produced nanotubes were characterized and compared. Their production resulted in ultramicropore tubes with an optimum surface area of $895 \mathrm{~m}^{2} \mathrm{~g}^{-1}$ obtained at $800^{\circ} \mathrm{C}$. The pore size distributions of those carbon molecular sieves were in the range of $0.26-0.29 \mathrm{~nm}$.

In a subsequent work of theirs (Baytar et al., 2018), the group produced activated carbons employing, what they found to give the best micropore and specific surface areas, a sequential mode of microwave and conventional thermal treatment of pistachio shells. In their work, the pistachio shells were cleaned, ovendried, crushed, powered, impregnated with equal amount of $\mathrm{ZnCl}_{2}$, microwaved, furnace-heated, sufficiently rinsed-to reach a neutral $\mathrm{pH}$, dried, and stored. Different microwave powers and microwave treatment times were tested. The activated carbons were subsequently characterized using TGA, DTA, infrared spectroscopy, SEM, specific surface area measurements, and tested for their adsorption capacity using methylene blue and iodine. The latter two were 331 and $1,276 \mathrm{mg}$ per $\mathrm{g}$ of adsorbent, respectively.

Moussavi and Khosravi (2011) studied the efficacy of raw pistachio hull powder adsorption capacity using surrogate solutions of methylene blue. They used pistachio green hull waste; the hull was air-dried for 3 days and subsequently powdered and sieved to sieve mesh 200. Methylene blue was shown to be adsorbed by pistachio hull waste. Pistachio hull waste was subjected to a number of tests, in a range of conditions.
Most research conducted on this topic, including the research conducted by Moussavi and Khosravi (2011), involved the study of the effects of solution acidity, the concentration of adsorbent and adsorbate, the contact time, and the employed temperature. Moussavi and Khosravi (2011) tested the $\mathrm{pH}$ range from 5 to 10 and found $\mathrm{pH}=8$ to be the optimum value with maximum adsorbance. The range of adsorbent and adsorbate concentrations studied were $0.5-3 \mathrm{~g} \mathrm{~L}^{-1}$ and $100-400 \mathrm{mg} \mathrm{L}^{-1}$, respectively. The concentration of the adsorbent was found to play an important role in the speed and efficacy of the removal of methylene blue. Tested contact time reached $70 \mathrm{~min}$ and temperature was tested in the range $20-50^{\circ} \mathrm{C}$. Practically complete removal of methylene blue was achieved at $\mathrm{pH} 8$, when the adsorbate concentration was $100 \mathrm{mg} \mathrm{L}^{-1}$ with a respective adsorbent concentration of $1.5 \mathrm{~g} \mathrm{~L}^{-1}$ following a 70 min treatment. Temperature also had an important effect. Adsorption was increased from just fewer than 400 to $\sim 600 \mathrm{mg}$ of adsorbate per gram of adsorbent by an increase of temperature from 20 to $50^{\circ} \mathrm{C}$. The Langmuir equation fit best with the equilibrium adsorption of methylene blue. The use of untreated pistachio shells in a powder form appears to thus form potential adsorbents of methylene blue from wastewaters.

In a similar study, Moussavi and Barikbin (2010) used the same type of raw pistachio hull powder to remove chromium VI from synthetic wastewaters. They tested the effects of $\mathrm{pH}$ in the range of $2-8$, the adsorbent concentration from $0.5 \mathrm{~g}$ $\mathrm{L}^{-1}$ up to $5 \mathrm{~g} \mathrm{~L}^{-1}$, the adsorbate concentration from 50 up to $200 \mathrm{mg} \mathrm{L}^{-1}$, and temperature in the range of $5-50^{\circ} \mathrm{C}$ on chromium (VI) adsorption. They achieved a removal of $\sim 116 \mathrm{mg}$ of adsorbate per gram of adsorbent at $\mathrm{pH} 2$ following treatment of an hour at room temperature. Adsorbate $\mathrm{Cr}^{6+}$ was extracted from the solution and was adsorbed at the same oxidation state. The Langmuir equation fit the equilibrium adsorption data well. Real industrial wastewaters were also employed in this study. Measurements employed $0.5 \mathrm{~L}$ of wastewater with $1,1.5$, and $2 \mathrm{~g} \mathrm{~L}^{-1}$ of adsorbent. The mixtures were stirred at $100 \mathrm{rpm}$; all measurements were conducted at $\sim 25^{\circ} \mathrm{C}$ and treatment lasted for different time-frames in the range of 3-60 $\mathrm{min}$. The addition of each of the aforementioned different amounts of the adsorbent powder produced an initial fast removal of $\mathrm{Cr}(\mathrm{VI})$ which then gradually increased with time approaching equilibrium. In all cases, $60 \mathrm{~min}$ of treatment resulted in a high percentage of 
TABLE 1 | Research summary on pistachio hulls as adsorbent feedstock.

\begin{tabular}{llll}
\hline Adsorbent $\quad$ Adsorbate/water Results & Rences
\end{tabular}

\section{TREATED HULLS}

Copper-doped zinc sulfide nanoparticles loaded on activated carbon formed by pistachio nut shell waste sieves- nanotubes produced via benzene deposition at a range of temperatures and deposition times

Activated carbons:Impregnation with $\mathrm{ZnCl}_{2}$ in $\mathrm{N}_{2}$; microwave $(2.45$ $\mathrm{GHz}$ ), and 1-30 min treatment and $600^{\circ} \mathrm{C}$ heating in cycles.

Chemical activation using $\mathrm{ZnCl}_{2}$ in

$\mathrm{N}_{2}$ at $600^{\circ} \mathrm{C}$ for $45 \mathrm{~min}$

c. Physical activation $60 \mathrm{~min}$ at $900^{\circ} \mathrm{C}$
Small pore carbon molecular
Physicochemically activated carbon at $700^{\circ} \mathrm{C}$ in a $\mathrm{CO}_{2}$-rich atmosphere

Mixtures of naphthol green $\mathrm{B}$
(NG-B) and phenol red (PH-R) in
aqueous synthetic solutions

aqueous synthetic solutions

NONE

For characterization purposes: Methylene blue and iodine

Uranium (VI) from surrogate aqueous solutions

Heavy metals: $\mathrm{Pb}$ and $\mathrm{Cu}$, from synthetic aqueous solutions ${ }^{1}$

Acid Violet 17 in surrogate wastewaters

Adsorption \& desorption studies $\mathrm{Cu}$ (II), Fe (II), Zn (II), Ni (II), and their mixtures in synthetic water solutions.

Real copper mine wastewaters.
Ultrasound assisted $(37 \mathrm{kHz}$, $320 \mathrm{~W}$ ), ambient temperature $50 \mathrm{ml}$ solution: initial NG concentration: $20 \mathrm{mg} \mathrm{L}^{-1}$, initial $\mathrm{PH}-\mathrm{R}$ concentration: $60 \mathrm{mg} \mathrm{L}^{-1}$; $0.035 \mathrm{~g}$ of adsorbent.

Best surface area of $895 \mathrm{~m}^{2} \mathrm{~g}^{-1}$ obtained at $800^{\circ} \mathrm{C}$. Pore size distributions in the range of $0.26-0.29 \mathrm{~nm}$

Effect of:microwave power (100-1,000 W)

Treatment time: 1-30 min Effect of microwave power inert gas and flow rate $\left(\mathrm{N}_{2}, \mathrm{Ar}\right.$, and $\mathrm{CO}_{2}$ ) 50-100 $\mathrm{mL} \mathrm{min}^{-1}$ Adsorbent $\mathrm{pH}$ neutral

$0.10 \mathrm{~g}$ of the activated carbon was equilibrated with $10 \mathrm{~mL}$ of typically $100 \mathrm{mg} \mathrm{L}^{-1} \mathrm{U}(\mathrm{VI})$ solution, for an hour. Particle size of adsorbent from 250 to $25 \mu \mathrm{m}$ Agitation for different intervals of time

from 5 to $240 \mathrm{~min}$

Effect of temperature (293.15-318.15 K) pH (2-8)

$10 \mathrm{~g} \mathrm{~L}^{-1}$ of biochar, produced at $550^{\circ} \mathrm{C}$

The effect of: $\mathrm{pH}(2-10)$, adsorbent $\left(0.2-4 \mathrm{~g} \mathrm{~L}^{-1}\right)$, adsorbate concentration (100 mg $\left.\mathrm{L}^{-1}\right)$, temperature $(30-60)^{\circ} \mathrm{C}$

For $\mathrm{Cu}(\mathrm{II})$, the effect of: $\mathrm{pH}:(2-7)$ temperature (298-360 K), kinetic study at $\mathrm{pH} 6.5$, and $\mathrm{T}=298 \mathrm{~K}$
At best: $\mathrm{pH}=3.2,0.035 \mathrm{~g}$ of adsorbent, 6 min of sonication 99\% removal.

No tests as adsorbents.

lodine numbers for untreated, microwave, and cyclic treatment: 180,878 , and 1,276 mg

$\mathrm{g}^{-1}$, respectively. lodine numbers increased only up to $200 \mathrm{~W}$ and up to 20 min of microwave treatment.

The highest iodine number value was obtained with $N_{2}$. Specific area and mean pore size of microwave and heating cyclic treatment was the largest 1.468 $\mathrm{m}^{2} \mathrm{~g}^{-1}$

The methylene blue number at the best conditions was $341 \mathrm{mg} \mathrm{g}^{-1}$

Physical adsorption.

Decrease of particle size increased adsorption.

Best $\mathrm{pH}=3.0$

Adsorption was endothermic and spontaneous.

Some structural changes at the solid-liquid interface.

Both practically fully adsorbed at initial $\mathrm{Pb}$ and $\mathrm{Cu}$ concentrations of $15 \mathrm{mg} \mathrm{L}^{-1} \mathrm{~Pb}$ was better adsorbed throughout.

Adsorption increased with $\mathrm{pH}$ to reach its best at $\mathrm{pH}=2$, the adsorbent kept at $80^{\circ} \mathrm{C}$ had the best performance

Magnetic activated carbon nanocomposites functionalized with sulfamic acid can be used for up to seven cycles.

Easy separation magnetically. Adsorption process was spontaneous and endothermic (best temperature the maximum studied). Best $\mathrm{pH}$ : 6.5 temperature and decreased with
Sahin et al., 2018

Masoudian et al., 2018

Baytar et al., 2018

Donat and Erden, 2016

Komnitsas et al. 2015 2011

Nejadshafiee and Reza Islami, 2020
Vijayalakshmi et al., nanocomposites functionalized Pyrolyzed at $750^{\circ} \mathrm{C}$ for $1 \mathrm{~h}$ under $\mathrm{N}_{2}$ atmosphere, activation via steam at $900^{\circ} \mathrm{C}$ for $10 \mathrm{~h}$. Chemical oxidation, treated by $50 \%$. $\mathrm{HNO}_{3}$ solutions $\left(69 \% \mathrm{HNO}_{3}\right)$ at a ratio of $2 \mathrm{~g} / 20 \mathrm{~mL}$. 
TABLE 1 | Continued

\begin{tabular}{|c|c|c|c|c|}
\hline Adsorbent & Adsorbate/water & Conditions & Results & References \\
\hline \multicolumn{5}{|l|}{ RAW HULL } \\
\hline $\begin{array}{l}\text { Three-day air-dried raw pistachio } \\
\text { hull, powdered and sieved to } \\
\text { sieve mesh } 200 \text {. }\end{array}$ & $\begin{array}{l}\text { Surrogate aqueous solutions of } \\
\text { methylene blue. }\end{array}$ & $\begin{array}{l}\text { Effect of: } \mathrm{pH}:(5-10) \text {, temperature } \\
\left(20-50^{\circ} \mathrm{C}\right) \text {, adsorbent } \\
\text { concentration }\left(0.5-3 \mathrm{~g} \mathrm{~L}^{-1}\right) \text {, } \\
\text { adsorbate initial concentrations } \\
\left(100-400 \mathrm{mg} \mathrm{L}^{-1}\right) \text {. }\end{array}$ & $\begin{array}{l}\text { Optimum adsorption at } \mathrm{pH}=8 \\
\text { and } 70 \text { min treatment at } \\
\text { adsorbate and adsorbent } \\
\text { concentrations of } 100 \mathrm{mg} \mathrm{L}^{-1} \\
\text { and } 1.5 \mathrm{~g} \mathrm{~L}^{-1} \text {, respectively. } \\
\text { Increased temperature } \\
\text { significantly increased adsorption. }\end{array}$ & $\begin{array}{l}\text { Moussavi and } \\
\text { Khosravi, } 2011\end{array}$ \\
\hline Raw pistachio hull powder. & $\begin{array}{l}\text { Chromium VI from synthetic } \\
\text { wastewaters and electroplating } \\
\text { wastewaters kinetics. }\end{array}$ & $\begin{array}{l}\text { The effects of: } \mathrm{pH}(2-8) \text {, } \\
\text { adsorbent concentration }(0.5-5 \mathrm{~g} \\
\left.\mathrm{L}^{-1}\right) \text {, } \mathrm{Cr}(\mathrm{VI}) \text { initial concentration } \\
\left(50-200 \mathrm{mg} \mathrm{L}^{-1}\right) \text {, temperature } \\
\left(5-50^{\circ} \mathrm{C}\right)\end{array}$ & $\begin{array}{l}\text { One hour of treatment sufficient to } \\
\text { reach equilibrium. } \\
\text { Removal of } \sim 116 \text { mg of } \\
\text { adsorbate per gram of adsorbent } \\
\text { at } \mathrm{pH} 2 \text { at ambient temperature. } \\
\text { Complete removal of } \mathrm{Cr}(\mathrm{VI}) \text { from } \\
\text { real wastewaters following } \\
\text { addition of appropriate adsorbent } \\
\text { quantity. } \\
\mathrm{Cr} \text { is adsorbed as } \mathrm{Cr}(\mathrm{VI})\end{array}$ & $\begin{array}{l}\text { Moussavi and } \\
\text { Barikbin, } 2010\end{array}$ \\
\hline Raw pistachio nut shell & $\begin{array}{l}\text { Remazol Red (C.I. 18221) } \\
\text { surrogate wastewater }\end{array}$ & $\begin{array}{l}\text { Taguchi method was applied to } \\
\text { determine optimum contact time; } \\
\text { agitation speed initial dye } \\
\text { concentration acidity, } \\
\text { temperature, adsorbent particle } \\
\text { size, and concentration }\end{array}$ & $\begin{array}{l}\text { Optimum conditions statistically } \\
\text { evaluated } 10 \text { min residence time } \\
100 \mathrm{rpm} \text { agitation speed, } \\
\text { adsorbate concentration } 25 \mathrm{mg} \\
\mathrm{L}^{-1} \mathrm{pH}, 2 \text {; temperature } 20^{\circ} \mathrm{C} \text {, } \\
\text { adsorbent particle size in the } \\
\text { range of } 0.025 \mathrm{~mm}-0.5 \mathrm{~mm} \text { and } \\
\text { adsorbent concentration } 100 \mathrm{mg} \\
\mathrm{L}^{-1}\end{array}$ & Toprak et al., 2012 \\
\hline Raw Antep pistachio shells & Lead (II) & $\begin{array}{l}\text { Effects of: Adsorbent initial } \\
\text { concentration }(0.5,1, \& 4 \mathrm{~g}) \text {, } \\
\text { adsorbate initial concentration }(5, \\
30,50 \text { and } 100 \text { ppm), initial } \mathrm{pH} \\
\text { (2.0-9.5), temperature }\left(30-60^{\circ} \mathrm{C}\right) \text {, } \\
\text { contact time }(5,20,45,60,90 \text {, } \\
\text { and } 120 \text { min) }\end{array}$ & $\begin{array}{l}\text { Best: initial } \mathrm{pH}=5.5 \text {, adsorbent } \\
=1.0 \mathrm{~g} \text {, initial } \mathrm{Pb}(\mathrm{II}) \text { concentration } \\
=30 \mathrm{ppm} \text {, temperature }=\text { of } \\
30^{\circ} \mathrm{C} \text {. Typical time length for } \\
\text { equilibrium }=45 \mathrm{~min}\end{array}$ & $\begin{array}{l}\text { Yetilmezsoy and } \\
\text { Demirel, } 2008\end{array}$ \\
\hline Other Applications & \multicolumn{4}{|c|}{$\begin{array}{l}\text { Formation of curly carbon appropriate for electrochemical use } \\
\text { as an anode, Xu et al., } 2018 \\
\text { Aluminum nitride synthesis, A1 Qadri et al., } 2018 \\
\text { Combustion material, Gomes da Silva et al., } 2018 \\
\text { Extraction of valuable phenolic compounds from the pistachio } \\
\text { hull, Özbek et al., } 2018 \\
\text { Soil amendment Komnitsas et al., } 2015\end{array}$} \\
\hline
\end{tabular}

adsorbate removal from the solution; this percentage varied according to the adsorbent quantity employed. In all cases removal was higher than $87 \%$ and practically $100 \%$ for the highest adsorbent concentration. The study indicated that this cheap and environmentally benign adsorbent demonstrated a high potential to remove this toxic heavy metal from wastewaters.

Another dye that can be removed from the pistachio nut shell is the Remazol Red (C.I. 18221) as Toprak et al. (2012) found in their research employing surrogate wastewater samples.

Donat and Erden (2016) used the hull of Antep pistachios to prepare and physicochemically activate carbon at $700^{\circ} \mathrm{C}$ in a carbon dioxide-rich atmosphere. The activated carbons formed were found to effectively adsorb physically and remove uranium (VI) from surrogate aqueous solutions. Therefore, they recommend this type of process as an application to prevent radioactive pollution via the implementation of processes for the removal of uranium from wastes in various stages through nuclear fuel production.

The production of biochar from pistachio shells was also studied by Komnitsas et al. (2015). They subjected pistachio hulls to slow pyrolysis in a temperature range of $250-650^{\circ} \mathrm{C}$ for $1 \mathrm{~h}$ at a heating rate of $10 \mathrm{C} \mathrm{m^{-1 }}$. The potential of biochar to remove heavy metals, namely $\mathrm{Pb}$ and $\mathrm{Cu}$, from synthetic aqueous solutions showed that both metal ions were practically totally adsorbed when $10 \mathrm{~g} \mathrm{~L}^{-1}$ of biochar, produced at $550^{\circ} \mathrm{C}$, was used in aqueous solutions with initial $\mathrm{Pb}$ and $\mathrm{Cu}$ concentrations of $15 \mathrm{mg} \mathrm{L}^{-1}$. The adsorption of $\mathrm{Pb}$ was more pronounced compared to $\mathrm{Cu}$ in all biochars tested.

The adsorption of $\mathrm{Pb}$ was also studied by Yetilmezsoy and Demirel (2008). Instead of biochars however, they used raw Antep pistachio shells as adsorbents of lead (II). They studied the dependence of adsorption on adsorbent concentration on 
the initial concentration of $\mathrm{Pb}$ (II) ions, initial $\mathrm{pH}$, measurement temperature, and contact time. An initial $\mathrm{pH}$ of 5.5, mass of adsorbent over the initial $\mathrm{Pb}$ (II) concentration was $1.0 \mathrm{~g}$, Aqueous solutions of $200 \mathrm{ml}$ containing $30 \mathrm{mg} \mathrm{ml}^{-1}$ of $\mathrm{Pb}$ (II) at $30^{\circ} \mathrm{C}$ gave the best performance, while a typical contact time to reach equilibrium was reached in $45 \mathrm{~min}$ with an over $90 \%$ removal of $\mathrm{Pb}(\mathrm{II})$.

Vijayalakshmi et al. (2011) collected pistachio nut shells and after a good washing and sun drying were treated with $18 \mathrm{~N}$ of sulphuric acid and were split into three groups, according to temperature, i.e., at room temperature, at $50^{\circ} \mathrm{C}$, and at $80^{\circ} \mathrm{C}$ for $24 \mathrm{~h}$, after which they were rinsed until a neutral $\mathrm{pH}$ was reached. They were subsequently characterized with a number of techniques and they were then employed in adsorption of Acid Violet 17 surrogate wastewaters experiments. The effect of $\mathrm{pH}$ and adsorbent and adsorbate concentrations and the process temperature were tested. Adsorption increased with temperature and decreased with $\mathrm{pH}$ to reach its best at $\mathrm{pH}=2$, reaching $\sim 100 \%$ of dye removal as the adsorbent quantity increased to reach $120 \mathrm{mg}$ in a $50 \mathrm{~mL}$ sample of $100 \mathrm{mg} \mathrm{L}^{-1} 1$ of dye solution. The adsorbent kept at $80^{\circ} \mathrm{C}$ had the best performance. The results fitted well to the pseudo second order kinetic equation.

In addition to their use as adsorbents, other means of their valorization have also been investigated. As such, Özbek et al. (2018) studied the extraction of valuable phenolic compounds from the pistachio hull using aqueous ethanol solutions of different concentrations and microwaves to assist the extraction. The effect of the extracting solvent concentration was studied. The antioxidant activity and the phenolic content of the extracts were also measured and studied. A $50 \%$ in ethanol aqueous solution gave maximum yield and maximum antioxidant activity according to the ORAC test. Other antioxidant activity tests gave generally similar results. Pure ethanol extracts displayed the minimum antioxidant activity. The key extracted phenolic compound was gallic acid (Özbek et al., 2018).

Gomes da Silva et al. (2018) studied the physicochemical properties and characterized pistachio shells as combustion material. They employed a number of techniques. The thermal and kinetic characteristics were assessed via thermogravimetric analysis in an oxygen rich environment from ambient temperature to $1,000^{\circ} \mathrm{C}$ employing different heating rates. The thermogravimetric curves showed a region where devolatilization of volatile matter occurs and a second one where biochar oxidation occurred.

Aluminum nitride synthesis from nut shells is another application that A1 Qadri et al. (2018) have conducted and applied to be patented.

Xu et al. (2018) used pistachio nut shells as raw material which after appropriate treatment, i.e., via appropriate hydrothermal treatment followed by a pyrolytic step, prepared curly carbon appropriate for electrochemical use as an anode. The physical properties of the produced hard carbons were characterized via several techniques. They constructed materials with a good reversible capacity and excellent long-term cycling and rate performances. Besides their charge transfer resistance was very small. Their work demonstrated that these shells can also find promising applications in that direction.
Nejadshafiee and Reza Islami (2020) developed a magnetic activated carbon nanocomposite from pistachio shell, modified by sulfamic acid. The material was characterized while adsorption and desorption studies were conducted with $\mathrm{Cu}$ (II), Fe (II), Zn (II), Ni (II), and their mixtures in synthetic water solutions and real copper mine wastewaters. The magnetic activated carbon nanocomposites functionalized with sulfamic acid were very efficient in heavy metal removal at $\mathrm{pH}=6.5$, they could be used in several cycles and they could be easily separated magnetically.

\section{Cashew Nut Shell}

Western Africa and India are the main producers of cashew nuts with 42 and $25 \%$ of the world production each. India and Vietnam are the main exporters of this nut.

Cashews (Figure 3) form an important source of primary production of many countries in the equatorial zone. In many places husks of them are removed in local factories, the nuts are packaged, and the shells are burnt or dumped causing environmental problems. The valorization of this waste can be used amongst others for the production of adsorbents.

Many physicochemical methods are being tested for the reduction of the concentration of textile dyes in wastewaters. However, their removal by means of adsorption using adsorbents produced by waste biomass has merits which render it a much better option compared to other techniques. Nutshells as adsorbents come at a low cost, they are available at ample quantities, technology does exist, and equipment designs to employ them in any scale are available and easy to implement and operate. Research so far indicates that they are highly efficient, they are fully biodegradable, and they can be used to remove dyes of any concentration.

N'goran et al. (2018) employed surrogate wastewaters containing lead and cadmium and studied the factors affecting their removal by means of adsorption on activated carbons which had been obtained from Shea and cashew nuts, collected from Côte d'Ivoire, which is one of the primary world producers of those nuts. As in studies mentioned earlier, the authors employed surrogate aqueous solutions rich in the aforementioned heavy metals and examined the conditions where their practically complete removal was attainable, by adjusting $\mathrm{pH}$, contact time, and adsorbent and adsorbate concentrations. They found that cashew and Shea nut shells, either individually or mixed, were capable of adsorbing the pollutants with the best performance at adsorbent concentration $12 \mathrm{~g} \mathrm{~L}^{-1}$ and $\mathrm{pH}$ 5.0. Adsorption of lead was almost complete while cadmium removal was $<94 \%$. The adsorption of $\mathrm{Pb}^{2+}$ on activated carbons produced by Shea hull was well-represented by the Langmuir model. Data obtained by activated carbons formed by cashew husks were better simulated by Freundlich's model. The data of the isotherms obtained from Cd adsorption fitted better with the model of Freundlich. The isotherms obtained from adsorption experiments involving the simultaneous presence of both adsorbents agreed with the Langmuir model which agreed well with both heavy metals adsorption when a mixture of the two activated carbons was employed. Kinetics in all cases followed the pseudo second order. They also conducted lead and cadmium adsorptive removal from natural waters contaminated with these two heavy metals. They 


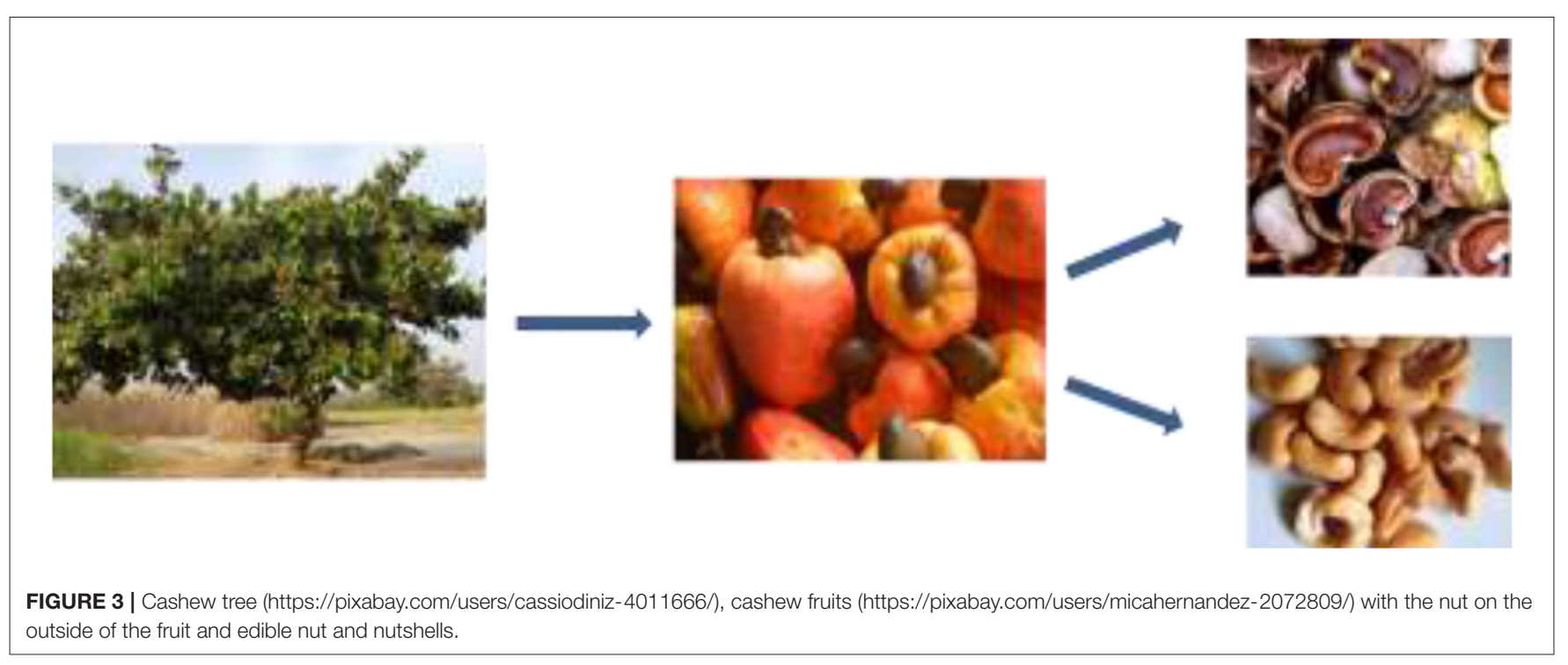

found that equilibrium removal with those waters was good but lower than that of the artificial solutions.

In a review of specific residual biomass-originating adsorbents, Pyrzynska (2019) focused on the adsorptive removal of cadmium (II) from surrogate wastewaters. Low-cost adsorbents are easily and locally available in large quantities. These natural adsorbents can have a substantially increased adsorptive capacity of cadmium (II) but simultaneously increase price as they require additional treatment while the gain in terms of environmental impact induced by their use may just be lost at best in the course of their modification. In the respective review, it was concluded that cashew nut shells lay between the best adsorbents for cadmium (II).

Siripatana et al. (2017) conducted a similar study employing cashew nut shells for the removal of lead. In their work they obtained cashew nut shells from a local factory. Thus, they utilized waste biomass, the collection management of which would not form a problem in the case of a scale-up operation. The treatment process for the formation of the adsorbent was simple: it involved washing, drying at $\sim 100^{\circ} \mathrm{C}$, grinding, sieving to $2.0 \mathrm{~mm}$, dehydrating the sorbent using impregnation in hexane, and subsequently drying again at $\sim 100^{\circ} \mathrm{C}$. The adsorbent was characterized and employed in a series of measurements. Lead adsorption was fast and increased with adsorbent concentration up to a value beyond which no additional adsorption was achieved. The kinetics of adsorption was well-simulated to pseudo second order kinetics.

Senthil Kumar and collaborators conducted several studies using cashew nuts shells. In Senthil Kumar et al. (2011a) the researchers used locally collected cashew nuts shells to form adsorbents of copper (II) ions following a very simple, economical, and practically environmentally benign process for their production. The shells were water-washed to have external dirt removed and they were left to dry at ambient temperature. The dried hulls were then powdered in a still mill. Subsequently, they were sieved; the particles of mesh size 200-30 were used for the adsorption experiments. The research involved, as in most of the above mentioned studies, the evaluation of the effects of temperature, $\mathrm{pH}$, adsorbent and adsorbate loading, and contact time. In their referred study the maximum adsorbance of copper ions was $85 \%$ at around a $\mathrm{pH}$ of 5 . Adsorption was minimum at $\mathrm{pH}=2$. The best temperature was $30^{\circ} \mathrm{C}$ and the experimental data fitted reasonably well to both Langmuir and Freundlich isotherm equations over the whole studied range of copper (II) ion concentration at $30^{\circ} \mathrm{C}$; the kinetics followed a pseudo second order rate.

In a subsequent study of theirs, Prabu et al. (2015) conducted a similar study employing modified cashew nut shells. The findings of the respective study indicated the same $\mathrm{pH}$ and temperature dependency as the one identified in Senthil Kumar et al. (2011a). The kinetics of adsorption was again best fitted as pseudo second order while the Freundlich isotherm equation was better at expressing their isotherms. This modified adsorbent was again very effective in the removal of copper ions. However, as mentioned by Pyrzynska (2019) modified adsorbents may not be economical to use and the environmental implications of the processes involved in their modifications have to be also considered.

The exact same process and inexpensively formed adsorbent as in Senthil Kumar et al. (2011a) was used by Senthil Kumar et al. (2011b) for the removal of nickel (II) from synthetic wastewaters. The adsorbent was characterized and the effect of $\mathrm{pH}$ and temperature were the same as in the case of copper, with $\mathrm{pH} 5$ and $30^{\circ} \mathrm{C}$, respectively, to give the best adsorption. The highest equilibrium adsorption achieved was just below $78 \%$. The sorption kinetics followed pseudo second order. The Freundlich equation fit best with their nickel (II) adsorption isotherm experimental data. They state that cashew nut shells can in general be easily collected locally and they are excellent economical adsorbents. As such, their use for the removal of nickel (II) ions from wastewaters could be considered as a promising potential option. 
In another work Senthil Kumar et al. (2011c) presented their research on the adsorption of $\mathrm{Pb}$ (II) from synthetic solutions. This time the researchers used cashew nut shells treated with sulphuric acid. The nut shells were rinsed with water, dried at ambient temperature, grinded to form a powder, and sieved. Particles of mesh size of 200-30 were then treated with concentrated sulphuric acid for 1 day. They were subsequently thoroughly washed until the rinsing solution $\mathrm{pH}$ was constant and equal to 4.0 . Finally they were dried at $80^{\circ} \mathrm{C}$ for $3 \mathrm{~h}$ and were characterized. The study, as with the previous ones, focused on the effect of $\mathrm{pH}$, contact time, temperature, and adsorbent and adsorbate concentrations. At $\mathrm{pH} 5$, in the span of concentrations studied and in the range of temperatures $30-60^{\circ} \mathrm{C}$, the removal of $\mathrm{Pb}$ (II) from the aqueous solution was always above $75 \%$ and was practically complete when lower adsorbate concentrations were used. The Freundlich adsorption isotherm best fitted the experimental isotherms. Kinetics was best fitted as a pseudo second order rate equation.

Similar studies have been performed by a number of researchers aiming at the removal of other important pollutants from wastewaters, mainly dyes and phenol with very encouraging results for such applications. Ponnusamy and Subramaniam (2013) used ground cashew nut shells which had been previously washed, dried, powdered, and sieved to 200-30 sieve mesh and were used without any further treatment for the removal of Congo red dye from surrogate aqueous solutions. The adsorbents were characterized and response surface methodology was employed to conclude that the study should focus on the effects of $\mathrm{pH}$, contact time, temperature, and adsorbent and adsorbate concentrations. The optimum conditions of their study, where removal of Congo red dye was complete were: $\mathrm{pH}, 3.2$, adsorbent concentration $24.76 \mathrm{~g} \mathrm{~L}^{-1}$, initial dye concentration, $20 \mathrm{mg} \mathrm{L}^{-1}$, 67 min contact time at $30^{\circ} \mathrm{C}$.

Congo red dye removal by adsorption on cashew nutshells was also conducted by Senthil Kumar et al. (2010). They employed the raw cashew nut shells as adsorbents researching $\mathrm{pH}$, temperature, and adsorbent and adsorbate concentrations in synthetic aqueous solution. They identified as optimum $\mathrm{pH}$ as 2 and temperature as $30^{\circ} \mathrm{C}$. Equilibrium was reached faster as the concentration of the adsorbate dropped and the concentration of adsorbent increased. Complete removal of the dye was possible when adequate adsorbent was present. The experimental data of the isotherms agreed well with all kinetic models tested with best fitting as follows: Redlich-Peterson $>$ Toth $>$ KobleCorrigan $>$ Sips $>$ Freundlich $>$ Langmuir $>$ Temkin $>$ DubininRadushkevich. The pseudo second order kinetics filled all dynamic data in the conditions tested.

Spagnoli et al. (2017) prepared activated carbons by chemical activation of Mozambique cashew nut shells with zinc chloride which they then used for the removal of methylene blue from surrogate wastewaters. Prior to their preparation cashew oil was extracted from the shells, thus providing the potential to offer further environmental and economic benefits from this waste valorization. They formed four different types of activated carbons. They were all produced in an identical way except the impregnation ratios. The impregnation ratios employed were $\left(\mathrm{ZnCl}_{2}\right.$ : shells) $0.5,1.0,1.5$, and 2 . All produced activated carbons were appropriately characterized and their adsorbing capacity was tested and compared with that of the rest. Their study involved activated carbons formation, characterization of the solid material and evaluation of each of them in the removal of methylene blue under different adsorbate concentrations for a given length of time. No $\mathrm{pH}$, temperature, or sorbent concentrations were tested. For the impregnated activated samples, the Langmuir isotherm model provided a better fit for the equilibrium adsorption data as opposed to that of Freundlich, which indicated a homogeneous monolayer adsorption. The experimentally obtained Langmuir adsorption equilibrium coefficient $\mathrm{K}_{\mathrm{L}}$ value increased with the increase in impregnation ratio, thus suggesting the favorability of the adsorption process upon impregnation. Furthermore, the maximum adsorption capacity values increased with impregnated activation. The best adsorption capacity value was found for the impregnation ratio 1.5.

Senthil Kumar and coworkers studied the removal of phenol from synthetic aqueous solutions using cashew nut shells which were only physically treated in the same manner as described above in their works for the removal of copper and nickel which is also presented in Senthil Kumar et al. (2011a) and Senthil Kumar et al. (2011b). The effects of pH, the process temperature, adsorbent and adsorbate concentration, and contact time at $\mathrm{pH}=5$ were tested in this research, while adsorbent characterization, adsorption kinetics, and isotherm fitting were also presented. The maximum adsorption was found at $\mathrm{pH}=5$ and all subsequent measurements were made at this $\mathrm{pH}$ value. In terms of temperature, the maximum removal of phenol was obtained at $30^{\circ} \mathrm{C}$. Under the conditions of the measurements, adsorption was initially very fast; equilibrium was reached in $30 \mathrm{~min}$ for all tested concentrations. The Langmuir isotherm provided the best adsorption data correlation. The pseudo second order kinetic model well-described the adsorption kinetics for the tested range of conditions (Senthil Kumar et al., 2011d).

A similar work was conducted by Kulkarni and co-workers. As opposed to Senthil Kumar et al. (2011d), Kulkarni et al. subjected the cashew nut shells to substantial treatment before using them. The cashew nut shells were washed with water and dried in sunlight for 2 days. Subsequently they were oven-dried at $100^{\circ} \mathrm{C}$ for $3 \mathrm{~h}$ and then heated at $400^{\circ} \mathrm{C}$ for $30 \mathrm{~min}$. They were subsequently powdered into a very fine form, were mixed with an equal amount of $3 \mathrm{M}$ sulphuric acid, and kept at $70^{\circ} \mathrm{C}$ for $6 \mathrm{~h}$. They were subsequently washed well and heated again for $6 \mathrm{~h}$. The adsorbent was characterized and employed in experiments involving phenol removal from surrogate wastewaters. Equilibrium was reached in their measurements after $4 \mathrm{~h}$ as opposed to the measurements employed by Senthil Kumar et al. (2011d) where equilibrium was reached after $30 \mathrm{~min}$. Senthil Kumar et al. (2011d) employed solutions with a maximum adsorbate concentration of $100 \mathrm{mg}$ $\mathrm{L}^{-1}$ with $20 \mathrm{~g} \mathrm{~L}^{-1}$ of adsorbent as opposed to the concentration employed by Kulkarni et al. (2018), who tested the range of adsorbate concentrations of $100-300 \mathrm{mg} \mathrm{L}^{-1}$ using $2.5-7.5 \mathrm{~g} \mathrm{~L}^{-1}$ of adsorbent. The data were well-represented by the Freundlich isotherm signifying multilayer chemisorption. The kinetic data obeyed the pseudo first order kinetic model. The monolayer 


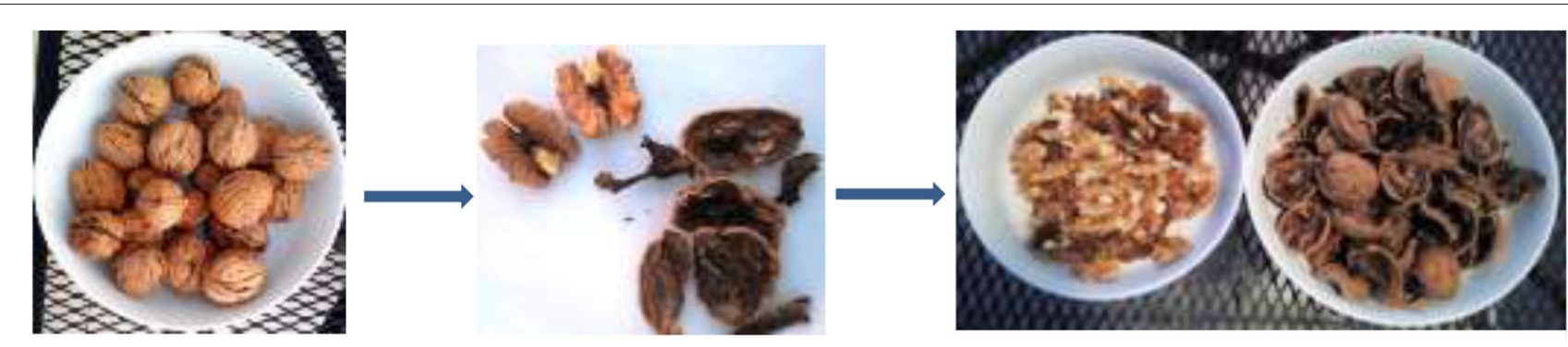

FIGURE 4 | Walnut edible nut and shells.

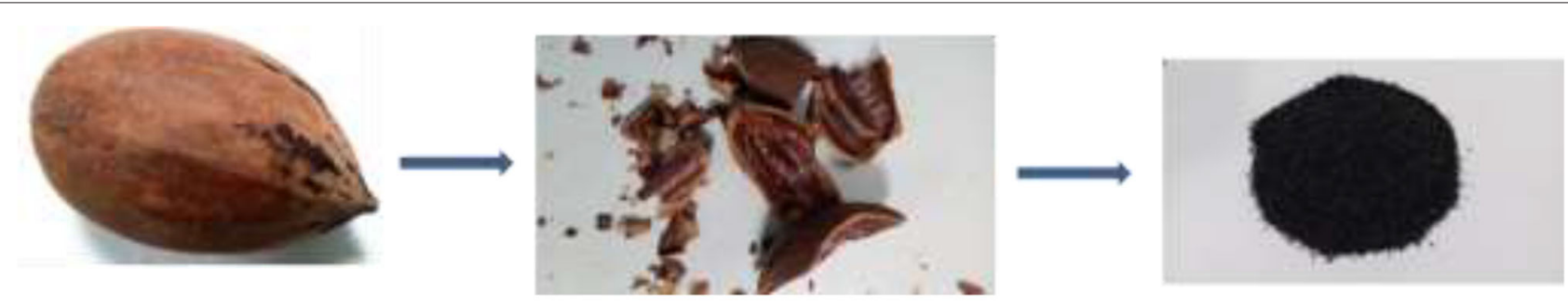

FIGURE 5 | Pecan nutshell for activated carbon formation.

adsorption capacity for the cashew nut shells at $\sim 40^{\circ} \mathrm{C}$ was $35.08 \mathrm{mg}$ of adsorbate per $\mathrm{g}$ of adsorbent, over six times higher than the one obtained by Senthil Kumar et al. (2011d) $(5.405 \mathrm{mg} / \mathrm{g})$. However, before comparing the two according to their suitability as adsorbents the costs and the environmental consequences of the pretreatment have to be considered in addition to necessary desorption studies and the evaluation of the cycles of each adsorbent (Kulkarni et al., 2018).

Further to being used as natural adsorbents, cashew nut shells can find different applications, for example in the valorization of cardanol. Cardanol resin is a byproduct of the cashew nut industry and a waste material extracted from cashew nut shell liquid. It is a novolac phenolic resin and as such it can find further application in, e.g., improving the mechanical properties of natural fibers as Dashtizadeh et al. (2019) presented in their work.

Geczo et al. (2020) developed activated carbons from cashews shells via impregnation with phosphoric acid and subsequent carbonization in the range of $400-700^{\circ} \mathrm{C}$, which were characterized and used for the removal of acetaminophen. The low density strongly acidic sites physically adsorbed acetaminophen, while high density strongly acidic sites caused hydrolysis of the drug. The highest adsorption was obtained by the adsorbent which was carbonized at $600^{\circ} \mathrm{C}$.

\section{Pecan Nutshell}

Walnut and pecan shells are shown in Figures 4, 5, respectively. Although the two nuts are distinctly different they are often addressed with the same name by the public in different countries. Bansode et al. (2003) studied the adsorption of mixtures of heavy metal ions employing carbons obtained from pecan nut shells, as the starting biomass. These were chemically and physically activated by phosphoric acid, steam, or carbon dioxide. The study was performed on surrogate wastewater solutions containing all three heavy metals simultaneously, i.e., $\mathrm{Cu}^{2+}, \mathrm{Pb}^{2+}, \mathrm{Zn}^{2+}$. The study revealed that $\mathrm{Pb}^{2+}$ and $\mathrm{Zn}^{2+}$ were preferentially adsorbed on the acid-activated carbon. Steam-activated pecan shell carbon adsorbed more $\mathrm{Cu}^{2+}$. Commercially available activated carbon (Filtrasorb 200) and carbon dioxide-activated pecan shell carbons were poor metal ion adsorbents. The adsorption data agreed with the Freundlich adsorption model.

Aguayo-Villarreal et al. (2017) produced eight types of activated carbons using pecan nut shells. In this study pecan nutshells were ground, sieved, and washed until a constant $\mathrm{pH}$ was obtained in the water washing solution and dried. Five of them were subjected to chemical activation with one of the following compounds $\mathrm{NaCl}, \mathrm{CaCl}_{2}, \mathrm{KCl}, \mathrm{CH}_{3} \mathrm{COOH}$, $\mathrm{H}_{2} \mathrm{SO}_{4}$, or $\mathrm{H}_{3} \mathrm{PO}_{4}$ and were subsequently physically activated with $\mathrm{CO}_{2}$. One was only physically activated with $\mathrm{CO}_{2}$ and the seventh was not subjected to any kind of activation. All seven kinds of activated carbons were pyrolyzed at $700^{\circ} \mathrm{C}$ after their chemical activation (whenever applicable). The pyrolysis lasted for $120 \mathrm{~min}$ in a nitrogen atmosphere; physical activation was also conducted at $700^{\circ} \mathrm{C}$ for the same length of time following sample pyrolysis. Activated carbons were proven to have been substantially enhanced via chemical and physical activation. They were much more efficient in removing ions, as opposed to the non-activated ones which were also produced by pecan nutshells via the same pyrolysis process. As per the adsorption of single metal ions from synthetic aqueous solutions, activated carbons which were subjected to chemical activation with potassium chloride were the most potent of all, followed by the ones treated 
with sodium chloride, then with calcium chloride, acetic acid, carbon dioxide, phosphoric acid and last the ones treated with sulphuric acid. Their affinities to the monometallic ions involved in this study were copper (II), zinc (II), nickel (II), and last of all cadmium (II). The adsorption capacity and behavior in binary mixtures of metal cations had great variation depending on the cation combinations. The tested adsorbents displayed different ion exchange properties. Different combinations of activation processes can possibly shape the activated carbon properties toward the desired outcome.

Zazycki et al. (2018) appropriately treated pecan nut shells so as to obtain bio-oil and biochar. The samples were washed, oven dried at $60^{\circ} \mathrm{C}$ for $8 \mathrm{~h}$, ground, and sieved. Particles with a diameter lower than $710 \mathrm{~mm}$ were used for biochar production. The heating of the powder took place at a rate of $10^{\circ} \mathrm{C}$ $\min ^{-1}$ up to $800^{\circ} \mathrm{C}$, where they were held for $1 \mathrm{~h}$ in an $\mathrm{N}_{2}$ atmosphere, which was kept until the biochar was cooled down to ambient temperature. The pyrolysis vapors were condensed biooil and biochar were collected, and the yield of the process was determined. The biochars were subsequently treated with $\mathrm{H}_{2} \mathrm{SO}_{4}$, washed, dried, powdered, characterized, and used in surrogate wastewaters to remove Reactive Red 141. The study involved the evaluation of the effect of $\mathrm{pH}$ (at $25^{\circ} \mathrm{C}$ with biochar and separately with fresh untreated pecan powder) and the dye concentration at different temperatures, for a contact time up to $4 \mathrm{~h}$, with a fixed adsorbent content in all cases. The best results were obtained at $\mathrm{pH} 2-3$ achieving an equilibrium concentration of around $85 \%$ of dye removal from the solution. The fresh, untreated pecan powder only gave $23 \%$ of equilibrium removal. In all cases equilibrium was attained within $80 \mathrm{~min}$. The adsorption was favored by the temperature decrease and the maximum adsorption was found for the lowest temperature employed, i.e., for $298 \mathrm{~K}$. The adsorption kinetics followed the pseudo second order model and the Freundlich model was better at representing the experimental isotherms.

Bello-Huitle et al. (2010) studied the removal of methylene blue and phenol by means of pecan and castile nutshells The nutshells were washed, dried in stove for $24 \mathrm{~h}$ at $110^{\circ} \mathrm{C}$, and were partially crushed. Phosphoric acid was mixed with the aforementioned nutshells with an impregnation proportion of $2 \mathrm{~g}$ of phosphoric acid per gram of raw material. They were then heated to $85^{\circ} \mathrm{C}$ under agitation for $4 \mathrm{~h}$; next they were strained and dried at $110^{\circ} \mathrm{C}$ for $24 \mathrm{~h}$. Subsequently, they were heated to $500^{\circ} \mathrm{C}$ at a rate of $10^{\circ} \mathrm{C} \mathrm{min}^{-1}$ and kept at that temperature for $3 \mathrm{~h}$. They were then cooled and washed with boiling and cold water, until $\mathrm{pH} 6.0$ was reached. Finally they were dried for $12 \mathrm{~h}$ at $110^{\circ} \mathrm{C}$. The produced activated carbons were characterized and used for the removal of methylene blue and phenol from synthetic samples. The experimental study involved a number of isotherms at $\mathrm{pH} 7$ and measurements employing different ratios of adsorbent to adsorbate concentration. The study addressed the issue of application in packed towers for wastewaters treatment. The Langmuir equation fitted best with the collected data for the entire range of tested concentrations. The fact that the Langmuir isotherm model had a better adjustment provides the indication that the employed activated carbon would not abruptly desorb substrate molecules if the surrounding concentration suddenly dropped. Moreover, the mechanical abrasion factor of the formed granules was good and appropriate for packed tower applications.

\section{Castor Seed Hull}

Mohammod et al. (2011) studied the removal of $\mathrm{Zn}^{2+}$ ions from aqueous solutions by means of castor seed hull powder and with activated carbons. The castor seed hull was washed with water then oven-dried overnight at $50-60^{\circ} \mathrm{C}$ and crushed. The produced powder was characterized employing several methods and was used to evaluate the rate of removal and the equilibrium isotherms of $\mathrm{Zn}^{2+}$ with the adsorbent under different $\mathrm{pH}$, and adsorbent and adsorbate concentrations. Adsorption increased with $\mathrm{pH}$ and the maximum uptake of zinc occurred at a $\mathrm{pH}$ of 6.0 , the maximum $\mathrm{pH}$ employed in this study. In all measurements employed in the present study, equilibrium was achieved earlier than $4 \mathrm{~h}$ of contact. The zinc adsorption process followed pseudo second order kinetics. The Langmuir model represented the experimental isotherms more satisfactorily. They also performed a series of measurements employing commercial activated carbon (Merck) but adsorption and kinetics were poorer when compared to the natural adsorbent.

As can be seen in Tables 1-3, most of the research conducted was of the same type: Use of different raw, powdered nut shells, biochars, or activated carbons from nutshells as adsorbents, which focused on adsorbents characterization, effect of $\mathrm{pH}$, effect of temperature, effect of initial concentration of adsorbate, and concentration of adsorbent. The ranges of temperature and $\mathrm{pH}$ explored by the cited researchers were very similar. Activated carbons and biochars were formed via appropriate protocols which involved treatments such as impregnation, pyrolysis, and carbonization with or without chemical and/or physical activation. Their formation involved similar protocols. Adsorbates were primarily dyes and heavy metals. A few studies dealt with phenol removal. One work (Donat and Erden, 2016) focused on the (successful) removal of uranium (VI). Nejadshafiee and Reza Islami (2020) treated real waste. They also examined desorption and the number of the adsorbent regeneration cycles. Such a study has not been conducted by any other researcher. Only one work (Geczo et al., 2020) involved adsorption of a drug active ingredient. The concentration of pharmaceuticals in waters and wastewaters is rapidly rising; their removal via adsorption can be promising as a prospect.

Senthil Kumar and his group have substantially worked with raw, untreated shells as well as with activated carbons developed from nut hulls treatment.

Although biochars and activated carbons have in most cases a higher efficiency, their production requires high temperature treatments, use of harmful chemicals, e.g., strong acids or alkalis and substantial treatment time, while it is naturally more costly.

Whenever the $\mathrm{pH}$ role was tested while using either untreated or treated pistachio shells, acidic $\mathrm{pH}$ was found to facilitate adsorption. Moussavi and Khosravi (2011) found that the optimum adsorbance of methylene blue on untreated pistachio hulls was optimized at alkaline $\mathrm{pH}$.

In the limited number of studies employing solutions with more than one compound, antagonistic adsorptions were 
TABLE 2 | Research summary on cashews hulls as adsorbent feedstock.

\begin{tabular}{llll}
\hline Adsorbent $\quad$ Adsorbate Results & Refitions
\end{tabular}

\section{RAW HULL}

Review of specific residual

biomass-natural adsorbents

Cashew nut shells were dried at $\sim 100^{\circ} \mathrm{C}$, impregnated in hexane, and heated again at $\sim 100 \mathrm{oC}$

Cashew shells: cleaned, dried at room temperature, powdered, sieved to mesh size 200-30
The exact same process as in Senthil Kumar et al. (2011a)

Cleaned, grinded, powdered cashew nut shells sieved to 200-30

Same as described in Senthil Kumar et al. (2011a) and Senthil Kumar et al. (2011b)
Cadmium (II) from surrogate

wastewaters

Lead from surrogate wastewaters

Copper (II) from surrogate wastewaters

Nickel II from synthetic wastewaters

Congo red dye from surrogate aqueous solutions

Phenol
$\mathrm{Pb}\left(\mathrm{NO}_{3}\right)_{2}$ for $\mathrm{Pb}^{2+}$ ions

Ion initial concentration 10-50 mg

$\mathrm{L}^{-1}$ and $10 \mathrm{~g}$ adsorbent

Contact times up to $1,500 \mathrm{~min}$

Temperature: $30^{\circ} \mathrm{C}$

The kinetics of adsorption was well-simulated to pseudo second order kinetics

Effects of:temperature 30, 40, 50, and $60^{\circ} \mathrm{C}$ for the initial copper (II) ion concentrations in the range of 10-50 $\mathrm{mg} \mathrm{L}^{-1}$ at a constant dose of $3 \mathrm{~g} \mathrm{~L}^{-1}$ and $\mathrm{pH}$ of 5

A series of such conical flasks were shaken for $30 \mathrm{~min}$ at a speed of $120 \mathrm{rpm}$ $\mathrm{pH}$ : $100 \mathrm{~mL}$ solution of $20 \mathrm{mg} \mathrm{L}^{-1}$ of copper (II) ion for a pH range of 2.0 to 8.0 at $30^{\circ} \mathrm{C}$

Adsorbent concentration: $0.1 \mathrm{~g}$ to $0.6 \mathrm{~g}$ in a $100 \mathrm{~mL}$ solution of $20 \mathrm{mg} \mathrm{L}^{-1}$ of copper (II) ion at pH 5.0, for a contact time of $30 \mathrm{~min}$ at $30^{\circ} \mathrm{C}$ And adsorbate loading: $0.3 \mathrm{~g}$ of with $100 \mathrm{~mL}$ of copper (II) ion solution of different initial concentrations $(10,20,30,40$, and $50 \mathrm{mg} / \mathrm{L}$ ) at $\mathrm{pH}$ value of 5.0 at $30^{\circ} \mathrm{C}$

Contact time: 5, 10, 15, 20, 25, $30,35,40,45,50,55$, and 60 min for an initial concentration in the range of 10-50 $\mathrm{mg} \mathrm{L}^{-1}$ of copper (II) ion solution at $\mathrm{pH} 5.0$, at $30^{\circ} \mathrm{C}$ Same as above

A response surface methodology was employed to conclude that the study should focus on the effects of $\mathrm{pH}$, contact time, temperature, and adsorbent and adsorbate concentrations

The effects of $\mathrm{pH}$, and the process temperature, adsorbent and adsorbate concentration, and contact time at $\mathrm{pH}=5$ adsorbent characterization, adsorption kinetics
Cashew nut shells lay between

the best adsorbents for cadmium (II)

Lead adsorption was fast Increased with adsorbent concentration up to an equilibrium value

Monolayer adsorption $20.00 \mathrm{mg} \mathrm{g}^{-1}$ of copper (II) ions at $\mathrm{pH} 5$ equilibrated in $30 \mathrm{~min}$ Maximum adsorbance at $\mathrm{pH} 5$ was $85 \%$

Adsorption was minimum at $\mathrm{pH}=$ 2 The best temperature was $30^{\circ} \mathrm{C}$
Pyrzynska, 2019

Siripatana et al., 2017

Senthil Kumar et al., $2011 a$
The effect of $\mathrm{pH}$ and temperature-same as in the case of copper The highest equilibrium adsorption achieved was just below 78\%

Congo red dye complete removal at: $\mathrm{pH}, 3.2$, adsorbent concentration $24.76 \mathrm{~g} \mathrm{~L}^{-1}$, initial dye concentration, $20 \mathrm{mg} \mathrm{L}^{-1}$, 67 min contact time at $30^{\circ} \mathrm{C}$

The maximum adsorption was found at $\mathrm{pH}=5$ The maximum removal of phenol was obtained at $30^{\circ} \mathrm{C}$ Equilibrium was reached in $30 \mathrm{~min}$ for all tested concentrations
Senthil Kumar et al., 2011b

Ponnusamy and Subramaniam, 2013

Senthil Kumar et al., 2011d 
TABLE 2 | Continued

\begin{tabular}{lll}
\hline Adsorbent & Adsorbate & Conditions \\
\hline TREATED & & \\
Activated carbons from Shea and & $\begin{array}{l}\text { Surrogate wastewaters containing } \\
\text { cashew nuts }\end{array}$ & $\begin{array}{l}\text { Effect of: } \mathrm{pH} \text {, contact time, and } \\
\text { adsorbent and adsorbate } \\
\text { concentrations }\end{array}$ \\
& $\begin{array}{l}\text { Also lead and cadmium } \\
\text { adsorptive removal from } \\
\text { contaminated natural waters }\end{array}$ & \\
&
\end{tabular}

Samples as in Senthil Kumar et al. $\mathrm{Pb}$ (II) from synthetic solutions (2011a) further treated with concentrated sulphuric acid for 1 day and rinsed until $\mathrm{pH}$ was 4.0, dried at $80^{\circ} \mathrm{C}$ for $3 \mathrm{~h}$ and characterized

Modified cashew nut shells via liquid-phase reduction involving impregnation with $\mathrm{Fe}^{2+}$ sonication and reduction of $\mathrm{Fe}^{2+}$ to $\mathrm{Fe}^{0}$ via $\mathrm{NaBH} 4$

Same as in Senthil Kumar et al. (2011a)

Four types of chemically activated carbons with impregnation in zinc chloride at different ratios: $\left(\mathrm{ZnCl}_{2}\right.$ : shells) 0.5, 1.0, 1.5 and 2 at $\sim 85^{\circ} \mathrm{C}$ for $2 \mathrm{~h}$, oven drying at $120^{\circ} \mathrm{C}, 2-\mathrm{h}$ carbonization in nitrogen, washed with $\mathrm{HCl}$ and washed with deionized water and dried at $120^{\circ} \mathrm{C}$
Cashew nut shells were washed, sun-dried, oven-dried at $100^{\circ} \mathrm{C}$ heated at $400^{\circ} \mathrm{C}$ for $30 \mathrm{~min}$, powdered into a very fine form, mixed with an equal amount of $3 \mathrm{M}$ sulphuric acid and kept at $70^{\circ} \mathrm{C}$ for $6 \mathrm{~h}$, washed well and heated again for $6 \mathrm{~h}$

Activated carbons from cashew nut shells
Methylene blue from surrogate wastewaters

Phenol removal from surrogate wastewaters

Cashew oil extraction with hexane, dried at $110^{\circ} \mathrm{C}$ Impregnation with $\mathrm{H}_{3} \mathrm{PO}_{4}$ at $\sim 85^{\circ} \mathrm{C}$ oven drying at $110^{\circ} \mathrm{C}$, carbonization in nitrogen, washed, and dried
Effect of $\mathrm{pH}$, contact time, temperature (30-60), and adsorbent concentration (100-500 $\mathrm{mg} \mathrm{L}^{-1}$ ) using $1 \mathrm{~g} \mathrm{~L}^{-1}$ adsorbate concentration agitated for $30 \mathrm{~min}$ at $80 \mathrm{rpm}$

20-100 mg/L of copper ions, $\mathrm{pH}$ (2.0-8.0), amount of the adsorbent $(0.5-3.0 \mathrm{~g} / \mathrm{L})$, and temperature $\left(30-60^{\circ} \mathrm{C}\right)$

$\mathrm{pH}$, temperature, adsorbent and adsorbate concentrations

Adsorbent characterization-pore size distribution

Effect of carbonization:

$300-700^{\circ} \mathrm{C}$

Adsorbate initial concentrations:

20, 40, 60, 80, 100, 150, 200,

and $250 \mathrm{ppm}$

$25 \mathrm{mg}$ of adsorbent was mixed with $20 \mathrm{~mL}$ of solution for $24 \mathrm{~h}$ Adsorbing capacity of each adsorbent tested and compared with each other
The adsorbent was characterized and employed in experiments involving

adsorbate initial concentrations of $100,150,200,250$, and $300 \mathrm{mg}$ $\mathrm{L}^{-1}$

Adsorbent concentrations 2.5-7.5 $\mathrm{g} \mathrm{L}^{-1}$

carbonization at 400-700 C Acetaminophen concentration: 10-70 mg/L

Adsorbent concentration: $12.5 \mathrm{mg}$ of $250 \mu \mathrm{m} 25 \mathrm{~mL}$ of adsorbate solution
Results

Those activated carbonsadsorb

heavy metals with best

performance at adsorbent concentration $12 \mathrm{~g} \mathrm{~L}^{-1}$ and $\mathrm{pH}$ 5.0

Equilibrium metal removal from wastewaters was good but lower than that of the synthetic solutions Adsorption of lead was almost complete; cadmium < 94\%

At $\mathrm{pH} 5$, $\mathrm{Pb}$ (II) removal was always above $75 \%$ and practically complete at low adsorbate concentrations

Equilibrium adsorbance: $45.039 \mathrm{mg}$ per $\mathrm{g}$ for $30 \mathrm{~min}$ treatment at $30^{\circ} \mathrm{C}$ and $\mathrm{pH} 6$ (optimal conditions)

They identified two as the optimum $\mathrm{pH}$ and temperature as $30^{\circ} \mathrm{C}$

Complete removal of the dye was possible when adequate adsorbent was present

Homogeneous monolayer adsorption

Best adsorption following impregnation ratio 1.5 Best adsorbent-carbonization temperature was $500^{\circ} \mathrm{C}$-with adsorption of $476 \mathrm{mg} / \mathrm{g}$ All chemically activated adsorbents had ultramicro-, micro-, and mesopores In lower impregnation ratios adsorption predominated in micropores Larger impregnated ratios adsorbents adsorbed by condensation mostly in mesopores

Un-impregnated carbon had no pores and the lowest yield

References

Senthil Kumar et al.,

20110

Prabu et al., 2015

Senthil Kumar et al., 2010

Spagnoli et al., 2017

Optimum conditions found by response surface methodology: $176 \mathrm{mg} \mathrm{L}^{-1}, 1.49 \mathrm{~g}$ of adsorbent at $39.02^{\circ} \mathrm{C}$

The monolayer adsorption capacity at $40^{\circ} \mathrm{C}$ was $35.08 \mathrm{mg}$ per $g$

All carbons were acidic High amount of strongly Acidic groups hydrolyze acetaminophen to adsorbed p-aminophenol and acetic acid 
TABLE 2 | Continued

\begin{tabular}{|c|c|c|}
\hline Adsorbent & Conditions & References \\
\hline & & $\begin{array}{l}\text { Lower amount of strongly acidic } \\
\text { solution results in physical } \\
\text { adsorption of acetaminophen }\end{array}$ \\
\hline Other applications & $\begin{array}{l}\text { Valorization of cardanol. Cardanol resin is a byproduct of the } \\
\text { cashew nut industry and a waste material extracted from } \\
\text { cashew nut shell liquid. It is a novolac phenolic resin and as } \\
\text { such it can find further application in for example improving } \\
\text { the mechanical properties of natural fibers as Dashtizadeh } \\
\text { et al., } 2019 \text { presented in their work }\end{array}$ & \\
\hline
\end{tabular}

TABLE 3 | Research summary on pecan hulls as adsorbent feedstock.

\begin{tabular}{|c|c|c|c|c|}
\hline Adsorbent & Adsorbate & Conditions & Results & References \\
\hline $\begin{array}{l}\text { Chemically and physically } \\
\text { activated pecan nut shells by } \\
\text { phosphoric acid, steam, or } \\
\text { carbon dioxide }\end{array}$ & $\begin{array}{l}\mathrm{Cu}^{2+}, \mathrm{Pb}^{2+}, \mathrm{Zn}^{2+} \text { in surrogate } \\
\text { wastewaters solutions }\end{array}$ & $\begin{array}{l}\text { Activated carbon concentration } \\
0.05,0.1,0.2,0.3,0.5,0.75 \text {, and } \\
1.0 \mathrm{~g} \text { per } 100 \mathrm{ml} \text { of metal ion } \\
\text { solution } \\
0.5 \mathrm{mM} \text { of each of the metal ion in } \\
\text { acetate buffer ( } 0.07 \mathrm{M} \text { sodium } \\
\text { acetate } \\
\text { and } 0.03 \mathrm{M} \text { acetic acid) were used }\end{array}$ & $\begin{array}{l}\mathrm{Pb}^{2+} \text { and } \mathrm{Zn}^{2+} \text { were preferentially } \\
\text { adsorbed on the acid-activated } \\
\text { carbon } \\
\text { Steam-activated pecan shell } \\
\text { carbon adsorbed more } \mathrm{Cu}^{2+} \\
\text { Carbon dioxide-activated carbons } \\
\text { are poor heavy metal adsorbents }\end{array}$ & Bansode et al., 2003 \\
\hline $\begin{array}{l}\text { Pecan nutshells ground, sieved, } \\
\text { washed, and dried } \\
\text { Five chemically activated with } \\
\mathrm{NaCl}, \mathrm{CaCl}_{2}, \mathrm{KCl}, \mathrm{CH}_{3} \mathrm{COOH}, \\
\mathrm{H}_{2} \mathrm{SO}_{4}, \mathrm{Or}_{3} \mathrm{PO}_{4} \text {, physically } \\
\text { activated with } \mathrm{CO}_{2} \\
\text { One physically activated with } \mathrm{CO}_{2} \\
\text { (C) One untreated (A), (B), and (C) }\end{array}$ & $\begin{array}{l}\text { Aqueous solutions of the heavy } \\
\text { metals } \mathrm{Zn} 2+, \mathrm{Cd} 2+, \mathrm{Ni} 2+, \\
\text { and } \mathrm{Cu} 2+\end{array}$ & $\begin{array}{l}\text { Characterization of activated } \\
\text { carbons; } \\
\text { adsorbent- } 2 \mathrm{~g} / \mathrm{L} \text {; stirred for } 24 \mathrm{~h} \\
\text { at } 30^{\circ} \mathrm{C}, \mathrm{pH} 5 \text {. } \\
\text { Single and binary solutions with } \\
\text { metal concentrations of } 0.5 \\
\text { and } 1 \mathrm{M} \text {. }\end{array}$ & $\begin{array}{l}\text { Improved activated carbons via } \\
\text { the combination of physical and } \\
\text { chemical activation } \\
\text { Different combinations of } \\
\text { activation processes can possibly } \\
\text { shape the activated carbon } \\
\text { properties toward the } \\
\text { desired outcome }\end{array}$ & $\begin{array}{l}\text { Aguayo-Villarreal } \\
\text { et al., } 2017\end{array}$ \\
\hline
\end{tabular}

were pyrolyzed at $700^{\circ} \mathrm{C}$ for

$120 \mathrm{~min}$ in a nitrogen atmosphere;

physical activation was also

conducted at $700^{\circ} \mathrm{C}$ for the same

length of time in the

following sample

Pecan nut shells were washed, oven dried at $60^{\circ} \mathrm{C}$ for $8 \mathrm{~h}$, ground, and sieved. Particles with a diameter lower than $710 \mathrm{~mm}$ were heated up to $800^{\circ} \mathrm{C}$, in an $\mathrm{N}_{2}$ atmosphere, treated with $\mathrm{H}_{2} \mathrm{SO}_{4}$ washed, dried, and powdered

The nutshells were washed, dried at $110^{\circ} \mathrm{C}$, crushed, impregnation with phosphoric acid (1 $\mathrm{g}$ of nutshells, $2 \mathrm{~g}$ phosphoric acid), heated to $85^{\circ} \mathrm{C}$, strained and dried at $110^{\circ} \mathrm{C}$, heated to $500^{\circ} \mathrm{C}$, cooled, washed until $\mathrm{pH} 6.0$, and dried at $110^{\circ} \mathrm{C}$
The adsorption of Reactive Red 141 in surrogate wastewaters, on activated carbons and raw untreated pecan nut shell

Methylene blue and phenol from synthetic solutions
Characterized as fresh untreated pecan (powder)

Effect of $\mathrm{pH}(2-8)$, temperature (298-328 K), dye concentration (50, 100, 200,

300 , and $500 \mathrm{mg} \mathrm{L}^{-1}$ ) for contact time (0 to $240 \mathrm{~min}$ ), with $0.05 \mathrm{~g}$ of adsorbent in $50 \mathrm{~mL}$ solution

For phenol isotherms, $0.15 \mathrm{~g}$ of 16-30 mesh was mixed with (5, $20,35,65,80$, and $95-\mathrm{mL}$ ) of a 500 ppm phenol solution For methylene blue 1,000 ppm of solution volume $(10,12,14,16$, $18,20,30,40$, and $50-\mathrm{mL}$ ) was mixed with $0.1 \mathrm{~g}$ of 8-18 mesh adsorbent $\mathrm{pH} 7 \mathrm{~T}=20^{\circ} \mathrm{C}$ stirred for $72 \mathrm{~h}$
Best pH 2-3

Equilibrium in $80 \mathrm{~min}$

Best temperature $298 \mathrm{~K}$

$85 \%$ of dye removal from the solution with activated carbons Untreated pecan powder only removed 23\%

Adsorption increased with temperature decrease

High maximum substrate adsorption Homogeneous surface Mechanical abrasion small Abrupt desorption low
Bello-Huitle et al.,

Zazycki et al., 2018 2010 identified. This highlights the need for further research and treatment of real wastewaters.
The similarities in the ranges and the kind of tested conditions and the narrow range of adsorbates makes the potential of 
comparisons quite limited. Most presented research involved removal of a single compound in small-scale bench experiments, where kinetic results were easy to obtain.

However, what is demonstrated by this field of research, which is a common outcome of all studies reported here, is that this type of waste biomass has significant potential and should be valorized toward that direction. Research of this type should embrace areas such as pesticide and fertilizers adsorption, in order to explore the potential of purification of fresh waters or the atmosphere and the adsorption of organic pollutants. Moreover, given the extent of the applications which this type of residual biomass can find, extensive research on real waste is imperative.

\section{CONCLUSIONS}

Nut shells have been investigated by researchers as raw materials or as precursors for the production of activated bio-carbons and biochars in order to be employed as adsorbents for a number of pollutants, mainly heavy metals and dyes. They appear to be a promising alternative to conventionally activated carbons in terms of efficiency. Most studies reported in this article were employing nut shells to form activated carbons following different types of treatment. Some used the natural shells in a powder form, others activated types of them, and other works involved the modification of the adsorbent.

All but one study involved only synthetic aqueous solutions. The researchers have demonstrated the ample capacity of the adsorbent to remove the studied compounds. Competitive adsorption has been the focus of very few papers. Moreover, in spite of their much promising performance as adsorbents, the adsorbing capacity of those materials can be substantially obstructed in natural waters or wastewaters. In particular in the event of synergistic treatment with microwaves or ultrasounds the presence of organic materials in aqueous solutions has to be considered. Ultrasounds and microwaves can break down

\section{REFERENCES}

A1 Qadri et al. (2018). United States Patent Application Publication Pub. In: No US 2018 / 0134560 Aluminum Nitride Synthesis From Nut Shells Pub. 17.

Aguayo-Villarreal, I. A., Bonilla-Petriciolet, A., and Muniz-Valencia, R. (2017). Synthesis of activated carbons from pecan nutshell and their application in the antagonistic adsorption of heavy metal ions. J. Mol. Liquids 230, 686-695. doi: 10.1016/j.molliq.2017.01.039

Bansode, R. R., Losso, J. N., Marshall, W. E., Rao, R. M., and R. J., Portier (2003). Adsorption of metal ions by pecan shell-based granular activated carbons, Bioresource Technology 89, 115-119. doi: 10.1016/S0960-8524(03)00064-6

Baytar, O., Sahin, Ö., Saka, C., and Agrak, S. (2018). Characterization of microwave and conventional heating on the pyrolysis of pistachio shells for the adsorption of methylene blue and iodine. Analyt. Lett. 51, 2205-2220 doi: 10.1080/00032719.2017.1415920

Bello-Huitle, V., Atenco-Fernandez, P., and Reyes-Mazzoco, R. (2010). Adsorption studies of methylene blue and phenol onto pecan and castile nutshells prepared by chemical activation. Rev. Mex. Ingen. Q. 9, 313-322. Available online at: http://www.redalyc.org/articulo.oa?id=62016236006

Coelho, J. A. P., Filipe, R. M., Robalo, M. P., Boyadzhieva, S., Cholakov, G., and Stateva R. P. (2020). Supercritical CO2 extraction of spent coffee grounds. Influence of co-solvents and characterization of the extracts. J. Supercr. Fluids 161:104825. doi: 10.1016/j.supflu.2020.104825 organic compounds forming toxic intermediates and as such create a different problem.

As Bello-Huitle et al. (2010) report, a further application for these materials as adsorbents could be as columns pre-treating water for desalination processes so as to minimize reverse osmosis costs by adsorbing suspended and soluble organic matter. Again, for such an application, competitive adsorption needs to be studied.

Another aspect which needs to be tested is the regeneration of the adsorbents, the recovery of the adsorbates, and naturally, the number of cycles which the adsorbents can complete before being disposed of.

Finally, in order to assess the positive environmental outcomes from such applications, a life cycle assessment is necessary. Moreover, the overall costs of their application have to be considered, especially in the cases where the adsorbents have been subjected to modifications.

\section{AUTHOR CONTRIBUTIONS}

All authors listed have made a substantial, direct and intellectual contribution to the work, and approved it for publication.

\section{FUNDING}

This project has received funding from the European Union's Horizon 2020 research and innovation program under the Marie Sklodowska-Curie grant agreement No. 778168.

\section{ACKNOWLEDGMENTS}

SG feels obliged to thank the Alexander S. Onassis Public Benefit Foundation for providing him funds for this research by means of a scholarship for a Ph.D. degree (G ZK 011-1).

Criado, A., and Martin, M. (2020). Integrated multiproduct facility for the production of chemicals, food and utilities from oranges. Ind. Eng. Chem. Res. 59, 7722-7731. doi: 10.1021/acs.iecr.0c00476

Dashtizadeh, Z., Khalina, A., Cardona, F., and Lee, C. H. (2019). Mechanical characteristics of green composites of short kenaf bast fiber reinforced in cardanol. Adv. Mater. Sci. Eng. 2019:8645429. doi: 10.1155/2019/8645429

Donat, R., and Erden, K. (2016). Adsorption of U(VI) ions from aqueous solutions by activated carbon prepared from Antep pistachio (Pistacia vera L.) shells. Radiochim. Acta 105, 359-367. doi: 10.1515/ract-2016-2637

Geczo, A., Giannakoudakis, D. A., Triantafyllidis, K., Ragab Elshaer, M., Rodríguez-Aguado, E., and Bashkova, S. (2020). Mechanistic insights into acetaminophen removal on cashew nut shell biomass-derived activated carbons. Environ. Sci. Pollution Res. doi: 10.1007/s11356-019-07562-0

Gomes da Silva, J. C, Francisco Alves, J. L., de Araujo Galdino, W. V., de Fátima Peralta Muniz Moreira, R, Jorge José, H., Felix de Sena, R., et al. (2018). Combustion of pistachio shell: physicochemical characterization and evaluation of kinetic parameters. Environ. Sci. Pollut Res. 25, 21420-21429. doi: 10.1007/s11356-017-8945-1

International nut \& Dried Fruits statistical. (2017/2018). Available online at: https://www.nutfruit.org/files/tech/1524481168_INC_Statistical_ Yearbook_2017-2018.pdf

Komnitsas, K., Zaharaki, D., Pyliotis, I., Vamvuka, D., and Bartzas, G. (2015). Assessment of pistachio shell biochar quality and its potential 
for adsorption of heavy metals. Waste Biomass Valoriz. 6, 805-816. doi: 10.1007/s12649-015-9364-5

Kulkarni, K., Sudheer, V., and Girish, C. R. (2018). Phenol adsorption from wastewater using cashew nutshells as adsorbent. Int. J. Eng. Technol. 7, 966-969. doi: 10.14419/ijet.v7i3.9771

Madeddu, C., Roda-Serrat, M. C., Christensen, K., El-Houri, R. B., and Errico, M. (2021). A biocascade approach towards the recovery of high-value natural products from biowaste: state-of-art and future trends. Waste Biomass Valoriz. 12, 1143-1166. doi: 10.1007/s12649-020-01082-6

Masoudian, N., Rajabi, M., Ghaedi, M., and Asghari, A. (2018). Highly efficient adsorption of Naphthol Green B and phenol red dye by combination of ultrasound wave and copper-doped zinc sulfide nanoparticles loaded on pistachio-nut shell: rapid removal of naphthol green b and phenol. Red. Appl. Organometal. Chem. 32:e4369. doi: 10.1002/aoc.4369

Mohammod, M., Sen, T. K., Maitra, S., and Dutta, B. K. (2011). Removal of $\mathrm{Zn}^{2+}$ from aqueous solution using castor seed hull. Water Air Soil Pollut. 215, 609-620. doi: 10.1007/s11270-010-0503-0

Moussavi, G., and Barikbin, B. (2010). Biosorption of chromium(VI) from industrial wastewater onto pistachio hull waste biomass. Chem. Eng. J. 162, 893-900. doi: 10.1016/j.cej.2010.06.032

Moussavi, G., and Khosravi, R. (2011). The removal of cationic dyes from aqueous solutions by adsorption onto pistachio hull waste. Chem. Eng. Res. Design 89, 2182-2189. doi: 10.1016/j.cherd.2010.11.024

Nejadshafiee, V., and Reza Islami, M. (2020). Intelligent-activated carbon prepared from pistachio shells precursor for effective adsorption of heavy metals from industrial waste of copper mine. Environ. Sci. Pollut. Res. 27, 1625-1639. doi: 10.1007/s11356-019-06732-4

N'goran, K. P. D. A., Diabaté, D., Yao, K. M., N’Guessan, L. B., Kouassi, G.nonsoro, U. P., et al. (2018). Lead and cadmium removal from natural freshwater using mixed activated carbons from cashew and shea nut shells Arabian. J. Geosci. 11, 498-510. doi: 10.1007/s12517-018-3862-2

Özbek, H. N., Halahlih, F., Gögüş, F., Yanik, D. K., and Azaizeh H. (2018). Pistachio (Pistacia vera L.) hull as a potential source of phenolic compounds: evaluation of ethanol-water binary solvent extraction on antioxidant activity and phenolic content of pistachio hull extracts waste and biomass. Valorization 9, 1-10. doi: 10.1007/s12649-018-0512-6

Ponnusamy, S. K., and Subramaniam, R. (2013). Process optimization studies of Congo red dye adsorption onto cashew nut shell using response surface methodology. Int. J. Industr. Chem. 4, 17-26. doi: 10.1186/2228-5547-4-17

Prabu, D., Parthiban, R., Senthil Kumar, P., Kumari, N., and Saikia, P. (2015). Adsorption of copper ions onto nano-scale zero-valent iron impregnated cashew nut shell. Desalin. Water Treatment 57, 6487-6502. doi: 10.1080/19443994.2015.1007488

Pyrzynska, K. (2019). Removal of cadmium from wastewaters with low-cost adsorbents. J. Environ. Chem. Eng. 7:102795. doi: 10.1016/j.jece.2018.11.040

Roda-Serrat, M. C., Andrade, T. A., Rindom, J., Lund, P. B., Norddahl, B., and Errico, M. (2020). Optimization of the recovery of anthocyanins from chokeberry juice pomace by homogenization in acidified water. Waste Biomass Valoriz. doi: 10.1007/s12649-020-01127-w

Sahin, Ö., Kaya, M., and Saka, C. (2018). Preparation and characterization of small pore carbon molecular sieves by chemical vapor deposition of pistachio shells. Analyt. Lett. 51, 2429-2440. doi: 10.1080/00032719.2018.1432630

Santzouk, G., Santzouk, S., Gerodimou, I., Tsaoulidis, D., and Dormousoglou, M. (2019). Opuntia ficus indica (Prickly pear): extraction and characterization of products with anti-age and antioxidant activity. Bulgar. Chem. Commun. 51, 52-55. doi: 10.34049/bcc.51.B.011

Senthil Kumar, P., Ramakrishnan, K., Dinesh Kirupha, S., and Sivanesan, S. (2011d). Thermodynamic, kinetic and equilibrium studies on phenol removal by use of cashew nut shell. Can. J. Chem. Eng. 89, 284-291. doi: $10.1002 /$ cjce.20396
Senthil Kumar, P., Ramalingam, S., Abhinaya, R. V., Thiruvengadaravi, K. V., Baskaralingam, P., and Sivanesan, S. (2011c). Lead(II) adsorption onto sulphuric acid treated cashew nut shell. Separat. Sci. Technol. 46, 2436-2449. doi: 10.1080/01496395.2011.590174

Senthil Kumar, P., Ramalingam, S., Dinesh Kirupha, S., Murugesan, A., Vidhyadevi, T., and Sivanesan, S. (2011b). Adsorption behavior of nickel (II) onto cashew nut shell: Equilibrium, thermodynamics, kinetics, mechanism and process design. Chem. Eng. J. 167, 122-131. doi: 10.1016/j.cej.2010. 12.010

Senthil Kumar, P., Ramalingam, S., Sathyaselvabala, V., Dinesh Kirupha, S., and Sivanesan, S. (2011a). Removal of copper(II) ions from aqueous solution by adsorption using cashew nut shell. Desalination 266, 63-71. doi: 10.1016/j.desal.2010.08.003

Senthil Kumar, P., Ramalingam, S., Senthamarai, C., Niranjanaa, M., Vijayalakshmi, P., and Sivanesan, S. (2010). Adsorption of dye from aqueous solution by cashew nut shell: Studies on equilibrium isotherm, kinetics and thermodynamics of interactions. Desalination 261, 52-60. doi: 10.1016/j.desal.2010.05.032

Siripatana, C., Khuenpetch, A., Phromrak, R., Saengngoen, W., and Nuithitikul, K. (2017). Kinetic study of adsorption of lead (II) ions onto cashew nut shells, journal of engineering and applied. Sciences12, 1819-1824. doi: 10.3923/jeasci.2017.1819.1824

Spagnoli, A., Giannakoudaki, D., and Bashkov, S. V. (2017). Adsorption of methylene blue on cashew nut Shell based carbons activated with zinc chloride: the role of surface and structural parameter. J. Mol. Liq. 229, 465-471 doi: 10.1016/j.molliq.2016.12.106

Toprak, F., Armagan, B., and Cakici, A. (2012). Systematic approach for the optimal process conditions of Reactive Red 198 adsorption by pistachio nut shell using Taguchi method. Desalin. Water Treat. 48, 96-105. doi: 10.1080/19443994.2012.698800

Vijayalakshmi, P., Sathya Selva Bala, V., Thiruvengadaravi, K. V., Panneerselvam, P., Palanichamy, M., and Sivanesan, S. (2011). Removal of acid violet 17 from aqueous solutions by adsorption onto activated carbon prepared from pistachio nut shell. Separat. Sci. Technol. 46, 155-163. doi: 10.1080/01496395.2010.484006

Xu, S. D., Zhao, Y., Liu, S., Ren, X., Chen, L., Shi, W., et al. (2018). Curly hard carbon derived from pistachio shells as high-performance anode materials for sodium-ion batteries. J. Mater. Sci. 53, 12334-12351. doi: 10.1007/s10853-018-2472-4

Yetilmezsoy, K., and Demirel, S. (2008). Artificial neural network (ANN) approach for modeling of $\mathrm{Pb}(\mathrm{II})$ adsorption from aqueous solution by Antep pistachio (Pistacia Vera L.) shells. J Hazard Mater 153, 1288-1300. doi: 10.1016/j.jhazmat.2007.09.092

Zazycki, M. I. A., Godinho, M., Perondi, D., Foletto, E. L., Collazzo, G. C., and Dotto, G. L. (2018). New biochar from pecan nutshells as an alternative adsorbent for removing reactive red 141 from aqueous solutions. J. Cleaner Produ. 171, 57-65. doi: 10.1016/j.jclepro.2017. 10.007

Conflict of Interest: The authors declare that the research was conducted in the absence of any commercial or financial relationships that could be construed as a potential conflict of interest.

Copyright (C) 2021 Papadaki, Mendoza-Castillo, Reynel-Avila, Bonilla-Petriciolet and Georgopoulos. This is an open-access article distributed under the terms of the Creative Commons Attribution License (CC BY). The use, distribution or reproduction in other forums is permitted, provided the original author $(s)$ and the copyright owner(s) are credited and that the original publication in this journal is cited, in accordance with accepted academic practice. No use, distribution or reproduction is permitted which does not comply with these terms. 